\title{
Molecular analysis of cox-1 and 18S rRNA gene fragments of Eimeria species isolated from endangered grouse: capercaillie (Tetrao urogallus) and black grouse (Tetrao tetrix)
}

\author{
Tomasz Stenzel $^{1}$ (D) Daria Dziewulska ${ }^{1} \cdot$ Maria Michalczyk $^{2} \cdot$ Dorota B. Lawreszuk $^{3} \cdot$ Andrzej Koncicki $^{1}$
}

Received: 16 August 2018 / Accepted: 3 December 2018 / Published online: 18 December 2018

(C) The Author(s) 2018

\begin{abstract}
This paper is the first record describing the molecular analysis of Eimeria species occurring in capercaillie (Tetrao urogallus) and black grouse (Tetrao tetrix) which inhabit northern Eurasia and are species critically endangered of extinction. Actions undertaken to protect endangered species, such as breeding individuals in closed aviaries, could allow saving those birds, but they also pose risk of accidental healing of invasive diseases, like coccidiosis. Therefore, an investigation was conducted on fecal samples collected from the capercaillies and black grouse originating from the Kirov region (Russia) and breeding centers located in Poland. Results indicate that the average prevalence of Eimeria revealed $72 \%$ (average $\mathrm{OPG}=3548$ ) and $80 \%$ (average $\mathrm{OPG}=$ 5220) in capercaillies and black grouse respectively. Most of the Eimeria spp. oocysts were non-sporulated; however, two different morphological types were observed. The phylogenetic analysis of cox-1 and 18S rRNA genes revealed the analyzed Eimeria sequences to belong to two species. In addition, it showed some similarities between both analyzed genes. Most of the sequences obtained from both grouse species coccidia belonged to one species partially homologous to the Eimeria spp. isolated from ring-necked pheasant (approx. 94 and 96\% for cox-1 and 18S rRNA genes, respectively). Two strains isolated from capercaillies imported from Russia were related to turkey coccidia: E. innocua and E. dispersa (97-99\% homology) in the cox-1 gene analysis and only one of them was related to those Eimeria species in the 18S rRNA gene analysis (98-99\% homology).
\end{abstract}

Keywords Black grouse $\cdot$ Capercaillie $\cdot$ Cox-1 gene $\cdot$ Genetic diversity $\cdot$ Phylogenetic analysis $\cdot 18 \mathrm{~S}$ rRNA gene

\section{Introduction}

Capercaillie (Tetrao urogallus) and black grouse (Tetrao tetrix) are large grouse birds that belong to the Galliformes

Section Editor: Berit Bangoura

Tomasz Stenzel

tomasz.stenzel@uwm.edu.pl

1 Department of Poultry Diseases, Faculty of Veterinary Medicine, University of Warmia and Mazury in Olsztyn, ul. Oczapowskiego 13, 10-719 Olsztyn, Poland

2 Department of Parasitology and Invasive Diseases, Faculty of Veterinary Medicine, University of Warmia and Mazury in Olsztyn, ul. Oczapowskiego 13, 10-719 Olsztyn, Poland

3 Institute of Biology, University of Białystok, ul. Konstantego Ciołkowskiego 1J, 15-245 Białystok, Poland order. They are boreal species breeding across the northern Eurasia. Since the mid-twentieth century, these two species have been facing a dramatic decrease in their numbers in Western Europe and in Poland. They are entered into the "Polish Red Book of Animals"- the capercaillie as a "critically endangered" species (CR category) and the black grouse as an "endangered" one (EN category) (Głowaciński 2001). The observed rapid decline in their numbers is caused by the loss of optimal habitats or forage base, excessive predatory pressure, geographical isolation, and depletion of the gene pool and anthropogenic factors (tourism, physical barriers such as forest planting fences, etc.) (Moreno-Opo et al. 2015; Thiel et al. 2011). The small genetic pool on the one hand leads to the inbred depression but can also predispose to parasitic invasions, which have been reported in the capercaillie (Isomursu et al. 2012). The response to this situation assumes implementation of numerous programs for active protection of the capercaillie and black grouse across Europe 
(Rutkowski et al. 2017; Siano and Klaus 2013; Strzała et al. 2015) to halt further loss of their number, enlarge their populations, and assure their long-term protection in Europe. These programs include releasing into the forest individuals from domestic breeding centers and birds translocated from the wild population from various geographical regions. The above actions undertaken to protect endangered species could allow for saving the capercaillie and black grouse. On the other hand, they pose risk of accidental healing of infectious/ invasive diseases or of introducing new infectious agents or their genetic variants to the new geographical locations. Keeping birds in unnatural conditions, like a closed breeding aviary, and high animal density also foster invasive diseases, especially with parasites of the simple life cycle. This phenomenon was also observed in the case of coccidia (Clark et al. 2017).

There are reports of coccidiosis infections in wildlife black grouse and capercaillie (Jankovska et al. 2012; Millán et al. 2008; Obeso et al. 2000). However, none of the coccidia that parasite on those species have been studied with the use of molecular methods. For the above reason, the aim of this study was to evaluate the genetic diversity of Eimeria (E.) species parasites isolated from fecal samples of capercaillies and black grouse originating from free-ranging breeding centers located in Poland and these transported from the Kirov region (Russia).

\section{Materials and methods}

\section{Ethical statement}

This study was carried out on fecal samples collected from the transport cages and aviaries, and no manipulations of live animals were done. The grouse were transported and kept as a part of the EU Project LIFE "Active protection of lowland populations of Capercaillie in the Bory Dolnoślaskie and Augustowska Primeval Forest" according to permission no. DZP-WG.6401.03.100.2016.km (release date 31 May 2016) issued by General Director of Environment Protection.

\section{Fecal samples}

In September 2016, 24 capercaillies (age not determined) were transported into the Augustowska Primeval Forest from the Kirov region (Russia) (translocation distance $1525 \mathrm{~km}$ ). Samples of their feces were collected from each transport cage immediately after the birds had been released. In October 2016, fecal samples were collected in aviaries of breeding centers inhabited by adult birds $(n=15)$. Additionally in August 2017, 18 samples were collected from young birds (3-4 months old) placed in adaptive aviaries and prepared for reintroduction with the "born to be free" method (Merta et al. 2015). Those capercaillies originated from the breeding center located in the Leżajsk State Forestry District (Southern East of Poland). The total number of examined samples was 57.

Fecal samples of adult black grouse $(n=10)$ were sent by the Jedwabno State Forestry District to Department of the Poultry Diseases, Faculty of Veterinary Medicine, University of Warmia and Mazury in Olsztyn (Poland) in June 2017.

\section{Parasitological screening}

The collected fecal samples were analyzed by flotation in a Darling fluid (a solution of saturated sodium chloride and glycerol in a ratio of 1:1). They were mixed on the mesh placed in a Petri dish. The resultant slurry was centrifuged at $800 \times \mathrm{g}$ for $5 \mathrm{~min}$. To determine the number of oocysts, coccidia were counted in a McMaster slide (OPG). The fecal samples containing oocysts were placed in a $2 \%(w / v)$ potassium dichromate solution, poured into Petri dishes, and kept at room temperature in the dark for sporulation.

\section{DNA extraction}

One hundred-microliter aliquots of supernatant from all centrifuged samples containing oocysts were transferred into a microcentrifuge tube containing $1400 \mu \mathrm{L}$ of $0.9 \%$ sodium chloride and centrifuged again at $2000 \times g$ for $5 \mathrm{~min}$. To damage the oocyst's wall, the resultant sediment was resuspended in $500 \mu \mathrm{L}$ of ATL lysis buffer (Qiagen, Germany). Next, the steel bead was added into each tube and tubes were placed in Tissuelyser II (Qiagen, Germany) homogenizer for 2 min with extensive shaking $(30 \mathrm{x} / 1 \mathrm{~s})$. After one step of $1 \mathrm{~min}$ incubation on ice, the samples were placed in Tissuelyser II again (the same conditions). Next, they were centrifuged at $7000 \times g$ for $1 \mathrm{~min}$. The following steps of DNA extraction were conducted with a DNeasy mini kit (Qiagen, Germany) in accordance with manufacturer instructions.

DNA concentration and purity was estimated using a NanoDrop 2000 (Thermo Scientific, USA) spectrophotometer, and the samples were stored at $-80{ }^{\circ} \mathrm{C}$ until further analysis.

\section{PCR amplification and sequencing}

Products of approximately $800 \mathrm{bp}$ of the mitochondrial cytochrome oxidase subunit 1 (cox-1) and approximately $1320 \mathrm{bp}$ of 18S rRNA gene were amplified with the primers designed by Miska et al. (2010) and Yang et al. (2012). Both PCRs were performed using a HotStarTaq Plus Master Mix (Qiagen, Germany) in a MasterCycler Pro thermocycler (Eppendorf, Germany). The composition of the reaction mixture used in both assays was as follows: $10 \mu \mathrm{L}$ of HotStarTaq Master Mix, $0.1 \mu \mathrm{L}$ of each primer (concentration $100 \mu \mathrm{M}$ ), $2 \mu \mathrm{L}$ of 
Coralload loading dye, and $2 \mu \mathrm{L}$ of template DNA. The reaction mixture was topped up to the volume of $20 \mu \mathrm{L}$ with ribonuclease-free water. The cox-1 gene fragment was amplified under the following conditions: initial denaturation at $95^{\circ} \mathrm{C}$ for 5 min followed by 34 denaturation cycles at $94{ }^{\circ} \mathrm{C}$ for $30 \mathrm{~s}$, annealing at $55^{\circ} \mathrm{C}$ for $30 \mathrm{~s}$, and chain elongation at $72{ }^{\circ} \mathrm{C}$ for $1 \mathrm{~min}$, whereas both steps of hemi-nested PCR amplification of the 18S rRNA gene were conducted under the following conditions: initial denaturation at $95{ }^{\circ} \mathrm{C}$ for $5 \mathrm{~min}$ followed by 45 denaturation cycles at $94{ }^{\circ} \mathrm{C}$ for $30 \mathrm{~s}$, annealing at $55^{\circ} \mathrm{C}$ for $30 \mathrm{~s}$, and chain elongation at $72{ }^{\circ} \mathrm{C}$ for $2 \mathrm{~min}$. The final elongation after the last cycle in both assays was performed at $72{ }^{\circ} \mathrm{C}$ for $10 \mathrm{~min}$. The amplification products were used for agarose gel electrophoresis whose results were read using the GelDoc XR+ gel imaging system (BioRad, Italy).

All of the amplified gene fragments were purified with a Concentrate Clean-Up kit (A\&A Biotechnology, Poland) and sequenced using Sangers method in Genomed S.A. (Poland).

\section{Phylogenetic analysis}

The resulting sequences were assembled in the SeqMan Pro application (DNASTAR, USA) and checked manually for sequencing errors using the same software. Sequences of the cox-1 and the 18S rRNA genes were compared with respectively 20 and 17 sequences of these genes of Eimeria species obtained from gallinaceous birds. The sequences used for comparison and their GenBank accession numbers are listed in Table 1. The obtained in this study and listed in GenBank sequences were aligned using the Clustal $\mathrm{W}$ and Clustal $\mathrm{V}$ methods and MegAlign software (DNASTAR, USA). All aligned sequences were trimmed at the same $5^{\prime}$ and $3^{\prime}$ ends and used for further analyses. Nucleotide and amino-acid identity matrices were generated with MegAlign Pro software (DNASTAR, USA). Phylogenetic trees were generated with the maximum likelihood method (Felsenstein 1981) in Mega 7 software (Kumar et al. 2016). Bootstrap values were calculated for 1000 replicates of the alignment. Gaps in the alignment were treated as missing characters. The phylogenetic trees were rooted with the sequence of Toxoplasma gondii (GenBank accession no. KM657810 and L37415).

\section{Accession numbers}

Sequences of Eimeria spp. isolates obtained in this study were submitted to the GenBank database to generate accession numbers (MG595956-MG595963 and MG825660MG825666).

\section{Results}

\section{Oocysts in fecal samples}

All samples obtained from the capercaillies imported from the Kirov region were positive for Eimeria spp. oocysts, whereas the prevalence of Eimeria parasites in the samples collected from birds located in Augustowska Primeval Forest and from Leżajsk State Forestry District was at 33 and 66\%, respectively. The average prevalence of Eimeria in the examined capercaillies oscillated at $72 \%$. The average OPG was 3548 (23319,436). Eighty percent of the samples collected from black grouse were positive for Eimeria spp. oocysts with average OPG at $5220(400-100,000)$.

Two different morphological types of oocysts (ellipsoid and round in shape) were observed. Both sporulating morphotypes were characterized by a smooth $0.6 \mu \mathrm{m}$-thick bi-layered wall. The oocysts measured $24.6 \times 12.6 \mu \mathrm{m}$ and $19.4 \times 17.7 \mu \mathrm{m}$, and their length/width $(\mathrm{L} / \mathrm{W})$ ratio was $1 / 0.51$ and 1/0.91, an average for the ellipsoid and round morphotypes, respectively. Oocyst micropyle and polar granule were absent. The oocysts contained four roughly ovoid sporocysts measuring $8.6 \times 4.5$ and $11.4 \times 7.4 \mu \mathrm{m}$ with a sporocyst $\mathrm{L} / \mathrm{W}$ ratio of $1 / 0.53$ and $1 / 0.64$ for the ellipsoid and round morphotype, respectively (Fig. 1). The sporulation time reached 36 and $48 \mathrm{~h}$ for the ellipsoid and round morphotype, respectively. From all the samples positive in

Table 1 The sequences of cox-1 and $18 \mathrm{~s}$ rRNA genes of different Eimeria species used to perform phylogenetic analysis

\begin{tabular}{lll}
\hline Scientific name & Accession number & \\
\cline { 2 - 3 } & Cox-1 & 18 s rRNA \\
\hline Eimeria (E.) acervulina & FJ236428 & KT184333 \\
E. adenoides & FR846201; FR846202 & KC305172 \\
E. brunetti & HM771675 & U67116 \\
E. dispersa & HG793048 & HG793041 \\
E. gallopavonis & HG793051 & KT184344 \\
E. innocua & HG793049 & HG793045 \\
E. irresidua & JQ993694 & HQ173832 \\
E. maxima & FJ236459 & DQ538348 \\
E. meleagridis & HG793046 & HG793040 \\
E. meleagrimitis & HG793050 & HG793044 \\
E. mitis & FR796699 & FR775302 \\
Eimeria sp. Meleagris gallopavo & HM117018 & HM117016 \\
E. nectrix & EU025108 & DQ136185 \\
E. pavonina & JN596590 & JN596589 \\
Eimeria sp. Perdix perdix & KJ547709 & - \\
Eimeria sp. Phasianus colchicus & HM117019; KJ547708 & HM117008 \\
E. praecox & KT184378 & FJ236371 \\
E. tenella & HM771676 & EF210326 \\
\hline
\end{tabular}


Fig. 1 Eimeria spp. oocysts isolated from investigated grouse species. a, c Non-sporulated oocysts. b, d Sporulated oocyst. Abbreviations: EW external wall, IW internal wall, S sporocyst, SB Stieda body a

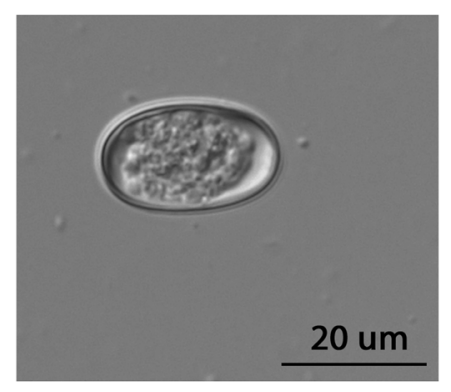

C

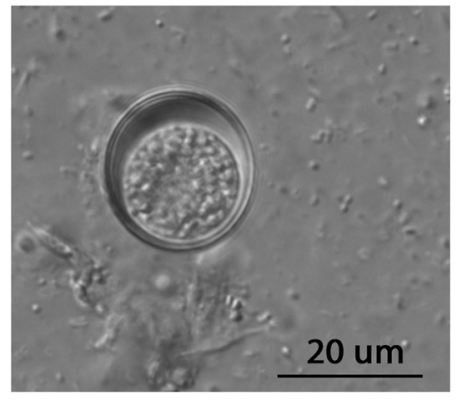

b

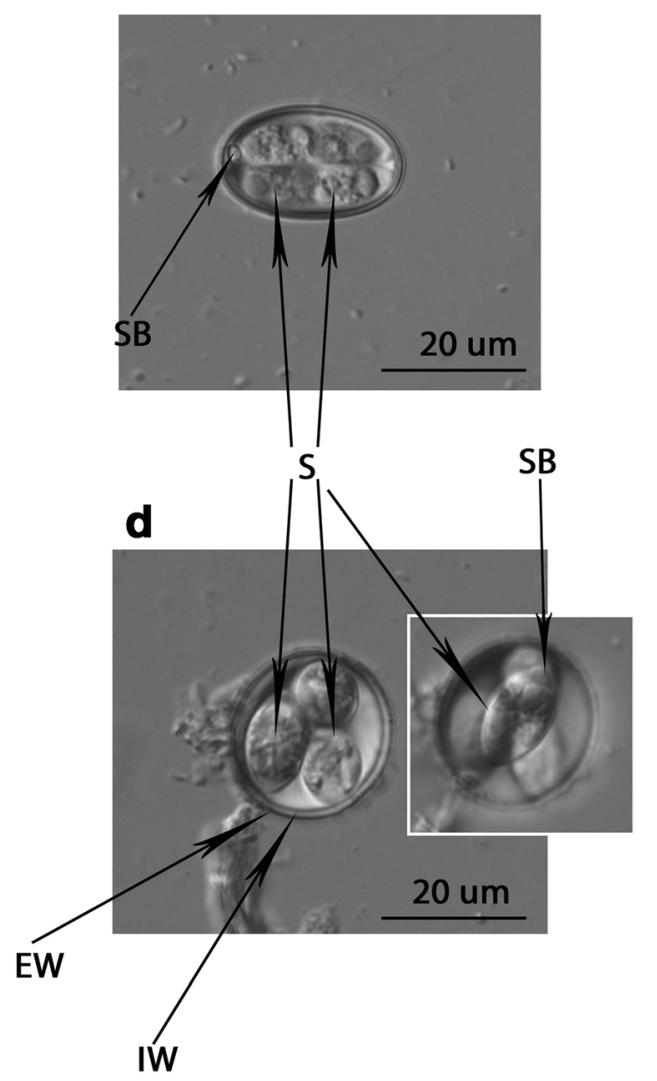

parasitological screening, only 8 (4 out of each grouse species) were positive in the cox-1 gene assay and 7 (3 from black grouse and 4 from capercaillie) in the $18 \mathrm{~S}$ rRNA assay.

All cox-1 gene and 18S rRNA gene amplicons were successfully sequenced and assembled into contigs (assembled sequences with the length of 690-786 and 1313-1404 nucleotides for cox-1 and 18S rRNA genes, respectively).

\section{Phylogenetic analysis}

The phylogenetic analysis of a cox-1 gene fragment revealed that in the context of this gene, the analyzed Eimeria sequences belonged to two species. The first one was represented by coccidia isolated from both grouse (capercaillie: Polish strain from Leżajsk State Forestry District and strain E4 Kirov, black grouse: all strains). Eimeria isolated from these species are clearly different from other known coccidia isolated from the gallinaceous birds (Fig. 2a). The sequences classified in these species were characterized by high homology (99.9$100 \%$ ) except the sequence belonging to the Leżajsk strain (97.5-97.6\%). The other two isolates obtained from capercaillies imported from the Kirov region were similar to turkey coccidia: E. innocua and E. dispersa (97.9-99.4\%) and were homologous at $99.7 \%$ to each other (Fig. 2a).

The average nucleotide identity of the cox-1 gene between Eimeria isolated from grouse and other gallinaceous birds was
$91.3 \%$, whereas the average nucleotide identity calculated only between grouse strains was higher and reached $95.5 \%$ (Fig. 2b). Numerous point mutations were found in the analyzed cox-1 gene fragment. Most of them were present in Kirov strains E1 (MG 595961) and E6 (MG 595963), where a total of 45 nucleotide substitutions were revealed in comparison to the other sequences. The most common substitutions included thymine instead of cytosine ( $\mathrm{T}>\mathrm{C}, 19$ mutations), adenine instead of thymine (A > T, 9 mutations), and cytosine instead of thymine ( $\mathrm{C}>\mathrm{T}, 6$ mutations). In the case of Leżajsk strain (MG 595960), 16 nucleotide substitutions common for E1 and E6 Kirov strains were found, whereas in Jedwabno (MG 595959) and 1.2 Jedwabno (MG 595957) strains, only one substitution was revealed ( $\mathrm{C}>\mathrm{A}$ ) (Fig. 3). The average identity of amino-acid sequences obtained after virtual translation was higher and reached $97.4 \%$ for all compared Eimeria sequences and in average $98.6 \%$ of grouse sequences (Fig. 2b).

The phylogenetic analysis of obtained fragment of the $18 \mathrm{~S}$ rRNA gene sequences revealed that most of the isolates belonged to one species (including isolate E6 Kirov) similar to the pheasant strain (96.3\% homology) except for the E1 Kirov isolate which belonged to other species and highly homologous to turkeys coccidia $E$. dispersa and E. innocua (98$99 \%$ homology). The average nucleotide identity of all analyzed sequences of this gene was $95.6 \%$, and the average nucleotide identity between the grouse sequences only was 


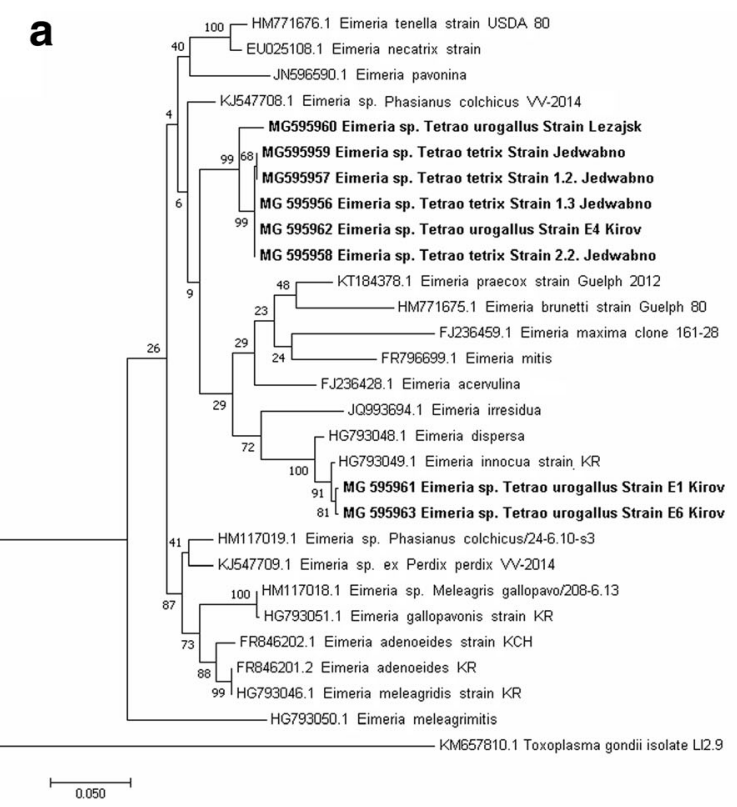

Fig. 2 a The maximum likelihood phylogenetic tree of 20 cox-1 gene nucleotide sequences of various Eimeria species available in the GenBank database and Eimeria isolates from investigated grouse species obtained in this study. The tree with the highest log likelihood (-4443.89) is shown. The percentage of trees in which the associated taxa clustered together is shown next to the branches. Initial tree(s) for the heuristic search were obtained automatically by applying Neighbor-Join and BioNJ algorithms to a matrix of pairwise distances estimated using the maximum composite likelihood (MCL) approach, and then selecting the

higher and reached $97.5 \%$ (Fig. 4). The highest number of point mutations in the analyzed fragment of the 18S rRNA gene was found in E1 Kirov strain (MG 825664), in b

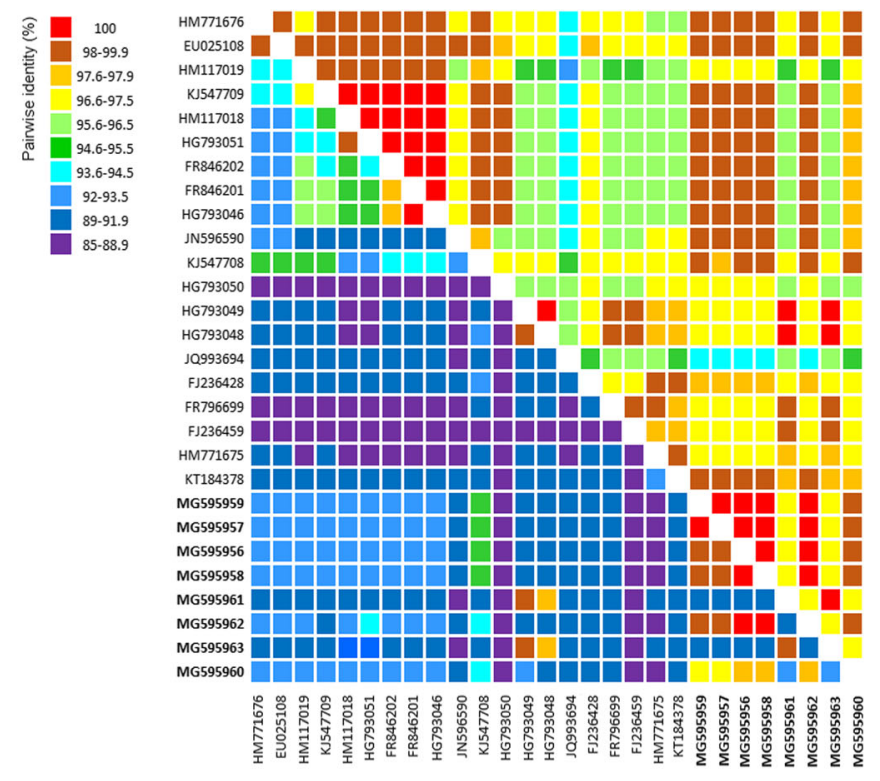

topology with superior log likelihood value. The tree is drawn to scale, with branch lengths measured in the number of substitutions per site. All positions containing gaps and missing data were eliminated. b Pairwise identity matrices calculated with the Clustal W method comparing cox-1 gene sequences of 20 Eimeria species from the GenBank database, and Eimeria isolates from capercaillie and black grouse obtained in this study with the percentage of nucleotide identity of cox-1 gene (bottom left) and the percentage of amino acids in protein encoded by this gene (top right)

comparison to the other strains, where a total of 29 nucleotide substitutions were noted, of which $\mathrm{C}>\mathrm{T}$ ( 8 mutations) and $\mathrm{T}>\mathrm{C}$ (6 mutations) were the most common ones. An insertion
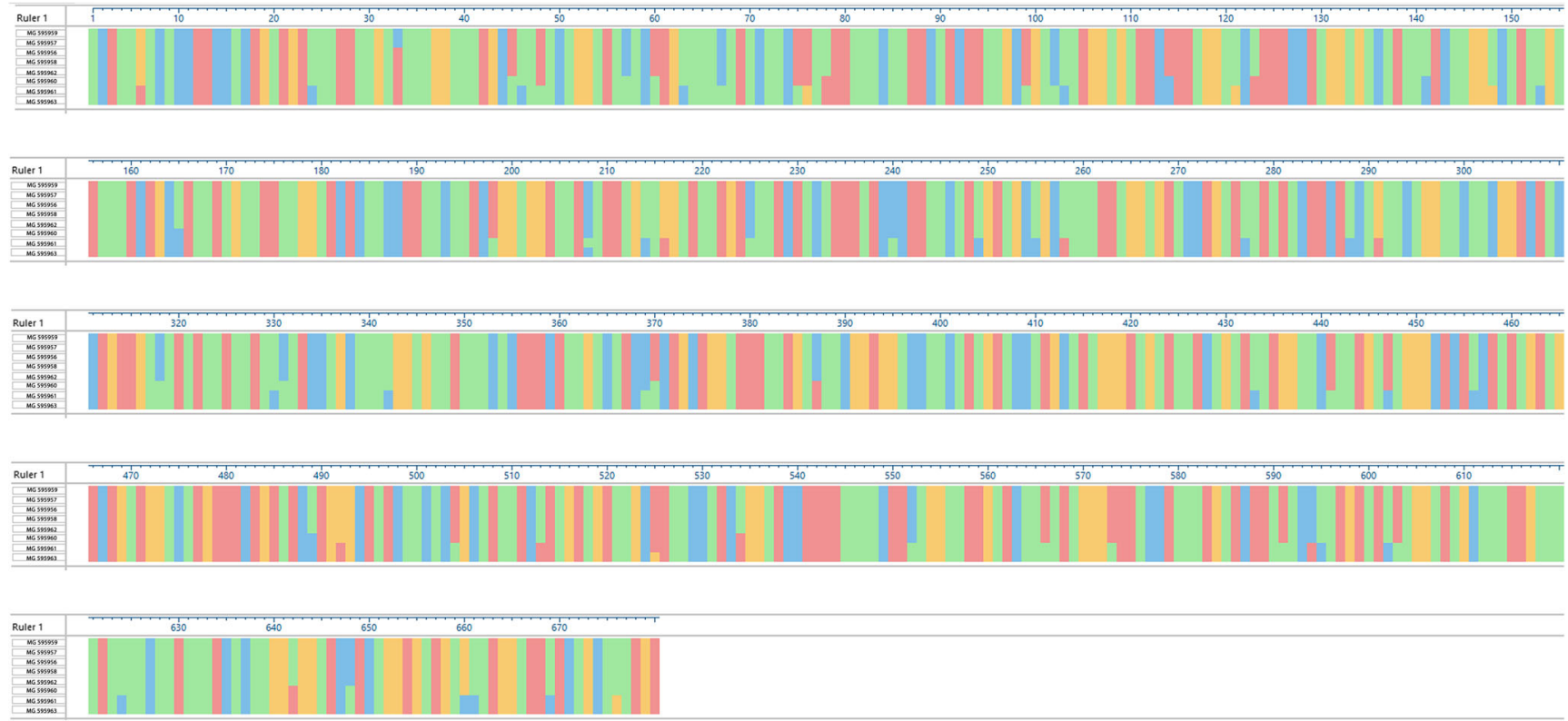

Fig. 3 Nucleotide substitutions in the analyzed cox-1 gene fragment among the revealed isolates of Eimeria spp. The alignment was created with CLUSTAL W in MegAlign software (DNASTAR, USA). The following background colors indicate the following nucleotides: red- adenine (A), blue — cytosine (C), orange — guanine (G), greenthymine (T). The positions where nucleotide substitution occurred are indicated by background color change 


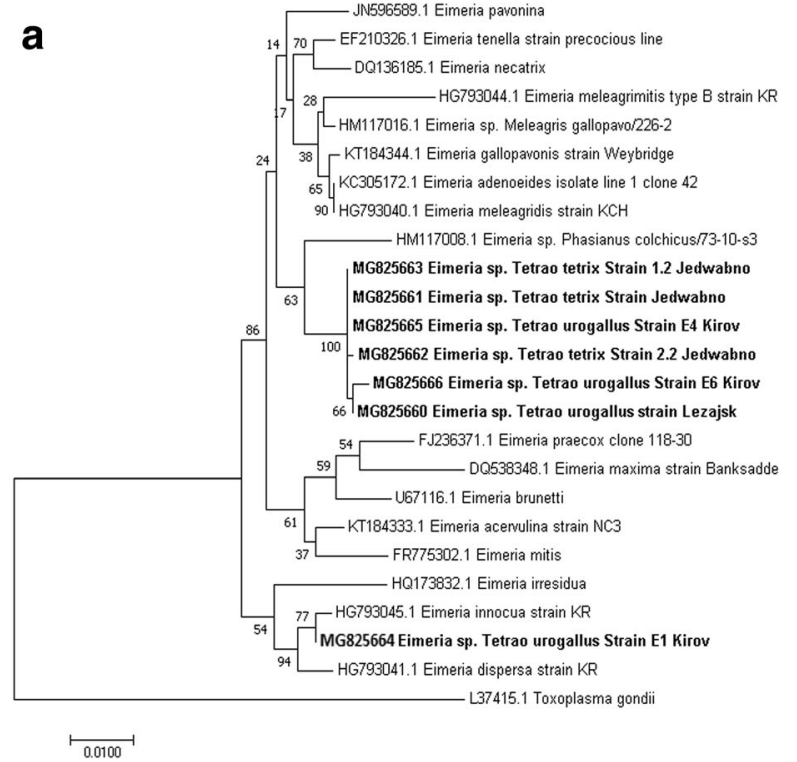

Fig. 4 a The Maximum likelihood phylogenetic tree of 17 18S rRNA nucleotide sequences of various Eimeria species available in the GenBank database and seven Eimeria isolates from capercaillie and black grouse obtained in this study. The tree with the highest log likelihood (-3697.28) is shown. The percentage of trees in which the associated taxa clustered together is shown next to the branches. Initial tree(s) for the heuristic search were obtained automatically by applying Neighbor-Join and BioNJ algorithms to a matrix of pairwise distances

of "CATT" (position 49-52 of the alignment) motif and single thymine (pos. 570 of the alignment) and a deletion of "TCT" motif in position 102-104 of the alignment were observed as well. Numerous single-nucleotide insertions were noted in the case of 2.2 Jedwabno strain (MG 8255662) where four thymine (pos. 300, 532, 544, and 553 of the alignment), three guanine (pos. 496, 511, 717 of the alignment), and one adenine insertion in pos. 595 of the alignment were found. Also, a deletion of single cytosine in pos. 626 of the alignment was observed. In the case of Leżajsk strain (MG 8255660), an insertion of single thymine in pos. 1218 of the alignment was found, whereas in E6 Kirov strain (MG 8255666), only four nucleotide substitutions were noted (Fig. 5).

\section{Discussion}

Our investigation has revealed that coccidia are highly prevalent in both grouse species, which is consistent with literature data (Jankovska et al. 2012; Millán et al. 2008; Obeso et al. 2000). However, the prevalence of coccidia in our study was much higher than in literature, which is probably due to the fact that the published data originated from investigations performed on wild grouse and not on birds kept in captivity. The high prevalence of Eimeria parasites in capercaillies transported from the Kirov region could be connected with bird exposure to stress during quarantine and transport, which

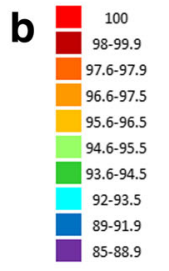

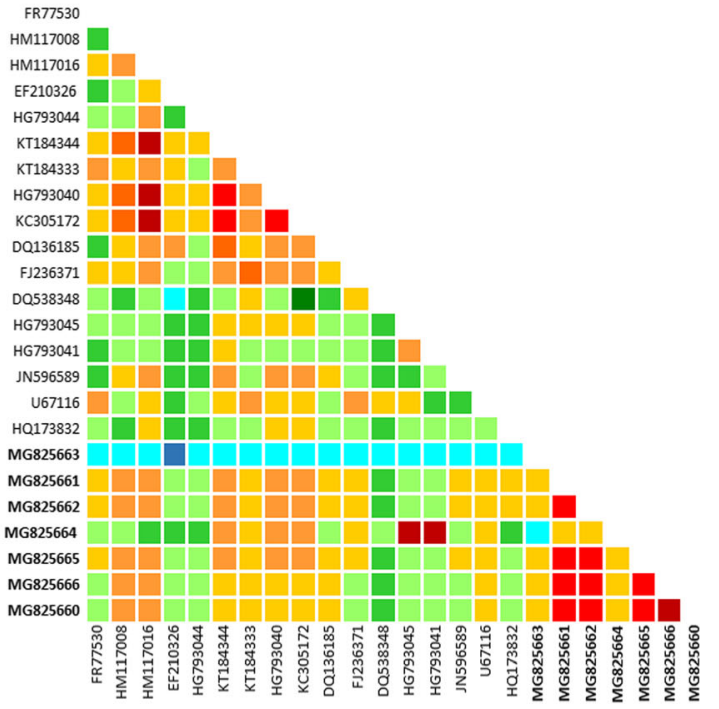

estimated using the maximum composite likelihood (MCL) approach, and then selecting the topology with superior log likelihood value. The tree is drawn to scale, with branch lengths measured in the number of substitutions per site. All positions containing gaps and missing data were eliminated. b Pairwise identity matrix calculated with the Clustal V method comparing 18S rRNA gene sequences of 17 Eimeria species from the GenBank database, and Eimeria isolates from investigated grouse species obtained in this study

could lead to their suppressed immunity. On the other hand, keeping animals in confined space promotes development of parasitic invasions, especially those with the simple life cycle. This could be the reason for high coccidia invasion in the investigated black grouse samples obtained from birds from one aviary. Little is known about Eimeria species occurring in grouse and their life cycle. However, the high prevalence of invasions in birds kept in captivity for reintroduction purposes suggests that they could lead to serious health problems resulting in interference of the reintroduction process. The high intensity of parasitic invasions has been shown to negatively influence a population by reducing clutch size, hatching success, and survival of young birds (Isomursu et al. 2012; Watson 2013).

Literature data suggest that most prevalent coccidia species occurring in black grouse is Eimeria lyruri (Jankowska et al. 2012). The coccidial sequences classified in our study as a separate clade (Figs. 2 and 4) probably belong to this Eimeria species, but we are unable to confirm this hypothesis because none of grouse Eimeria sequences is available in the GenBank database. There is also data about various coccidia species prevailing in capercaillie and black grouse including $E$. nadsoni, E. procera, and $E$. tetricis, but description of those species is scant and the data is very old and possibly out of date (Haase 1939; Pav and Zajicek 1974).

Our investigation demonstrated that the molecular method for coccidia detection in fecal samples was much less sensitive 


\section{-}

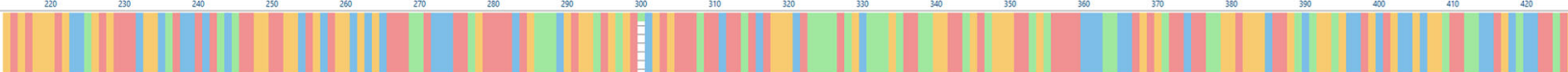
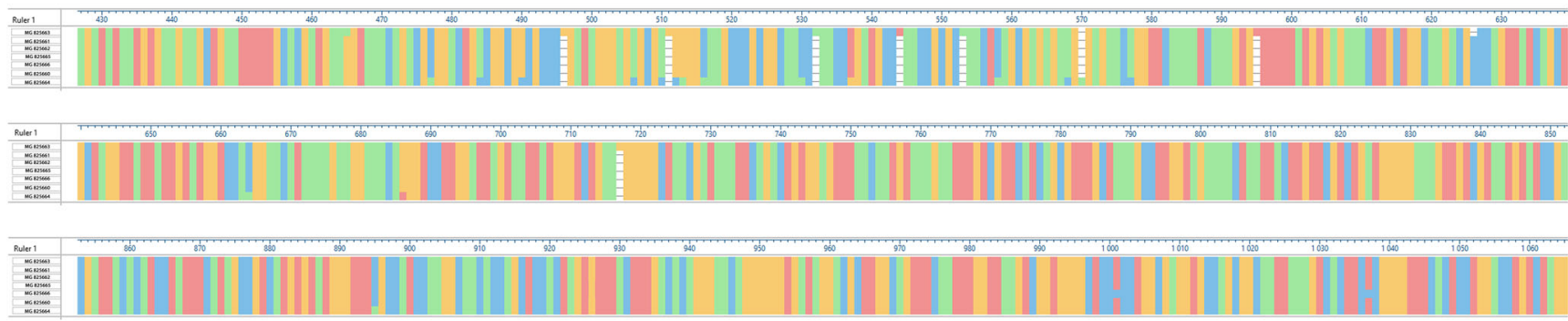

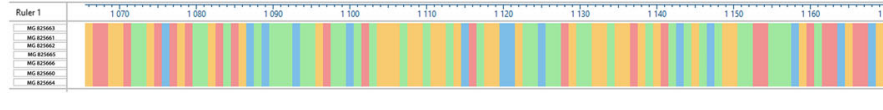

Fig. 5 Mutations in the analyzed 18S rRNA gene fragment among the revealed isolates of Eimeria spp. The alignment was created with CLUSTAL $\mathrm{W}$ in MegAlign software (DNASTAR, USA). The following background colors indicate the following nucleotides: redadenine (A), blue - cytosine $(C)$, orange - guanine $(G)$, green-

than the traditional microscopic examination of the flotation fluid, because only 8 of the 49 samples positive in microscopy evaluation were positive in the cox-1 assay and only 7 were positive in the 18S rRNA assay. In fact, only the samples in which oocyst count was high proved to be useful for PCR assays and further molecular analyses. The above could be explained by difficulties in DNA extraction from oocysts caused by their robust wall or by insufficient disruption of oocysts. Similar observations were made by other authors (Honma et al. 2011; Bertram et al. 2015).

The parasitological screening revealed that two morphotypes of eimeriid oocysts were present in the analyzed fecal samples. This suggests invasion of two different species of coccidia in both grouse species. The newest data presented by Ogedengbe et al. (2018) suggests that the morphologybased classification could be insufficient for proper Eimeria classification, and that molecular analysis is more reliable in this respect. Sequencing of small genome regions, such as mitochondrial cytochrome oxidase subunit 1 (cox-1) locus and 18S rRNA gene, has been commonly used to infer the relatedness of field Eimeria isolates (Clark et al. 2017). The phylogenetic analysis of cox-1 gene fragment performed with the maximum likelihood suggests two coccidia species to occur in capercaillie and black grouse what is convergent with parasitological examination. One of them is characteristic only for investigated grouse species and is related (approximately 94\%) to the Eimeria spp. strain isolated from ring-necked pheasants (acc no. KJ547708) (Fig. 2b). This species was the most prevalent ( 6 of 8 sequences) and was present in capercaillie from the Kirov region and from Leżajsk State Forestry District, and also in black grouse from the thymine (T). The positions where nucleotide substitution occurred are indicated by background color change, whereas white color indicates deletion of a single nucleotide or a motif in the aligned sequences. Insertion of a motif or a single nucleotide in a single sequence results in the virtual deletion in the other sequences after alignment

Jedwabno State Forestry District. It is well known that each coccidia species is highly specific to the host species, but our results suggest that this Eimeria species could occur in both capercaillie and the black grouse. We have also shown that there is no correlation between host species, host geographical origin, and nucleotide sequence of the analyzed gene fragment. The second species includes coccidia related to E. innocua and E. dispersa occurring in turkeys (approximately $98 \%$ homology) (Fig. 2b).

The phylogenetic analysis of the obtained partial $18 \mathrm{~S}$ rRNA sequences showed a slight difference in classification of Eimeria spp. Kirov E6 strain in comparison to cox-1 gene fragment analysis, and this result is consistent with findings reported by other authors (Miska et al. 2010; Hauck and Hafez 2012). The above differences could result from various extents of mutation and recombination processes in both of the analyzed genes (Miska et al. 2010). Nevertheless, some similarities between both analyzed genes were observed. Most of the sequences obtained from investigated grouse coccidia belonged to one species partially homologous to the Eimeria isolated from ring-necked pheasant (approx. 96\% for $18 \mathrm{~S}$ rRNA genes) while E1 Kirov strain is related to E. innocua and $E$. dispersa (98-99\% homology). The only difference is classification of the E6 Kirov strain obtained from capercaillie in the analyses of both gene sequences. The 18S rRNA gene is more conservative than cox-1 gene is (the average homology of all analyzed sequences was 95.6 and $91.3 \%$, respectively) (Figs. $2 \mathrm{~b}$ and $3 \mathrm{~b}$ ). Compared to the $18 \mathrm{~S}$ rRNA gene, the cox-1 gene is quickly evolving (sequence divergence rate of $1-2 \%$ per million years) and for this reason, the cox-1 gene sequences are a better base for the identification and 
phylogenetic analysis than the 18S rRNA gene sequences (ElSherry et al. 2013; Ogedengbe et al. 2018). Summarizing, the phylogenetic tree based on mitochondrial gene sequences is in this case more reliable.

To conclude, this paper constitutes the first report of the molecular characterization of an Eimeria species isolated from capercaillie and black grouse. The morphological and molecular analyses suggest that two species of coccidia could be present in both black grouse and capercaillie. From the reason of limited knowledge, further investigations are needed with the use of coupled parasitological and molecular analyses.

Acknowledgements The authors would like to thank Tomasz Gałęiathe Chief Forester of Głęboki Bród State Forestry District, Marek Tredowski-the Chief Forester Head of Jedwabno State Forestry District and Zenon Szkamruk - the Chief Forester of Leżajsk State Forestry District who have kindly provided grouse fecal samples for investigation.

Funding Publication supported by KNOW (Leading National Research Centre) Scientific Consortium "Healthy Animal—Safe Food," decision of the Ministry of Science and Higher Education No. 05-1/KNOW2/ 2015.

\section{Compliance with ethical standards}

Ethical statement This study was carried out on fecal samples collected from the transport cages and aviaries, and no manipulations of live animals were done. The grouse were transported and kept as a part of the EU Project LIFE "Active protection of lowland populations of Capercaillie in the Bory Dolnoślasskie and Augustowska Primeval Forest" according to permission no. DZP-WG.6401.03.100.2016.km (release date 31 May 2016) issued by General Director of Environment Protection.

Conflict of interest The authors declare that they have no conflict of interest.

Open Access This article is distributed under the terms of the Creative Commons Attribution 4.0 International License (http:// creativecommons.org/licenses/by/4.0/), which permits unrestricted use, distribution, and reproduction in any medium, provided you give appropriate credit to the original author(s) and the source, provide a link to the Creative Commons license, and indicate if changes were made.

Publisher's Note Springer Nature remains neutral with regard to jurisdictional claims in published maps and institutional affiliations.

\section{References}

Bertram MR, Hamer GL, Snowden KF, Hartup BK, Hamer SA (2015) Coccidian parasites and conservation implications for the endangered whooping crane (Grus americana). PLoS One 10:e0127679

Clark EL, Tomley FM, Blake DP (2017) Are Eimeria genetically diverse and does it matter? Trends Parasitol 33:231-241

El-Sherry S, Ogedengbe ME, Hafeez MA, Barta JR (2013) Divergent nuclear $18 \mathrm{~S}$ rDNA paralogs in a turkey coccidium, Eimeria meleagrimitis, complicate molecular systematics and identification. Int J Parasitol 43:679-685
Felsenstein J (1981) Evolutionary trees from DNA sequences: a maximum likelihood approach. J Mol Evol 17:368-376

Głowaciński Z (ed) (2001) Polish Red Data Book of Animals. Vertebrates. PWRiL, Warszawa, pp 173-177

Haase A (1939) Untersuchungen uber die bei deutschen Wildhuhnern vorkommenden Eimeria-Arten. Arch Protistenkunde 92:329-383

Hauck R, Hafez M (2012) Description of Eimeria pavonina (Coccidia) of peafowl in Germany. Avian Dis 56:238-242

Honma H, Suyama Y, Watanabe Y, Matsumoto F, Nakai Y (2011) Accurate analysis of prevalence of coccidiosis in individually identified wild cranes in inhabiting and migrating populations in Japan. Environ Microbiol 13:2876-2887

Isomursu M, Rätti O, Liukkonen T, Helle P (2012) Susceptibility to intestinal parasites and juvenile survival are correlated with multilocus microsatellite heterosigosity in the Capercaillie (Tetrao urogallus). Ornis Fennica 89:109-119

Jankovska I, Bejcek V, Langrova I, Válek P, Vadlejch J, Čadková Z (2012) Black grouse in Czech Republic and its parasites. Helminthologia 49:78-81

Kumar S, Stecher G, Tamura K (2016) MEGA7: molecular evolutionary genetics analysis version 7.0 for bigger datasets. Mol Biol Evol 33: 1870-1874

Merta D, Kobielski J, Krzywiński A, Theuerkauf J, Gula R (2015) Mother-assisted rearing ('born to be free' method) increases post -release survival and reduces the exploratory movements of young Capercaillies. Eur J Wildl Res 61:299-302

Millán J, Gortazar C, Ballesteros F (2008) Parasites of the endangered Cantabrian capercaillie (Tetrao urogallus cantabricus): correlates with host abundance and lek site characteristics. Parasitol Res 103:709-712

Miska KB, Schwarz RS, Jenkins MC, Rathinam T, Chapman HD (2010) Molecular characterization and phylogenetics analysis of Eimeria from turkeys and gamebirds: implications for evolutionary relationships in Galliform birds. J Parasitol 96:982-986

Moreno-Opo R, Afonso I, Jiménez J, Fernández-Olalla M, Canut J, GarcíaFerré D, Piqué J, García F, Roig J, Muñoz-Igualada J, González LM, López-Bao JV (2015) Is it necessary managing carnivores to reverse the decline of endangered prey species? Insights from a removal experiment of mesocarnivores to benefit demographic parameters of the Pyrenean capercaillie. PLoS One 10:e0139837

Obeso JR, Rodriguez LD, Álvares I, Niňo E, del Campo HC (2000) Intestinal parasites in the Cantabrian capercaillie Tetrao urogallus cantabricus: a coprological study. Ardeola 47:191-195

Ogedengbe ME, El-Sherry S, Ogedengbe JD, Chapman HD, Barta JR (2018) Phylogenies based on combined mitochondrial and nuclear sequences conflict with morphologically defined genera in the eimeriid coccidia (Apicomplexa). Int J Parasitol 48:59-69

Pav J, Zajicek D (1974) The incidence of coccidioses in tetraonid birds (Tetraonidae) from Czechoslovak hunting areas. Vestn Cesk Spol Zool 38:52-60

Rutkowski R, Zawadzka D, Suchecka E, Merta D (2017) Conservation genetics of the capercaillie in Poland - delineation of conservation units. PLoS One 12:e174901

Siano R, Klaus S (2013) Capercaillie Tetrao urogallus release projects in Germany after 1950 - a review. Vogelwelt 134:3-18

Strzała T, Kowalczyk A, Łukaszewicz E (2015) Reintroduction of the European Capercaillie from the Capercaillie breeding Centre in Wisła Forest District: genetic assessment of captive and reintroduced populations. PLoS One 10:e0145433

Thiel D, Jenni-Eiermann S, Palme R, Jenni L (2011) Winter tourism increases stress hormone levels in the Capercaillie Tetrao urogallus. Ibis 153:122-133

Watson MJ (2013) What drives population-level effects of parasites? Metaanalysis meets life-history. Int J Parasitol Parasites Wildl 2:190-196

Yang R, Fenwick S, Potter A, Elliot A, Power M, Beveridge I, Ryan U (2012) Molecular characterization of Eimeria species in macropods. Exp Parasitol 132:216-221 